\title{
Xylene Sensor Using Double-layered Thin Film and Ni-Deposited Porous Alumina
}

\author{
Tomo Akiyama, Yurie Ishikawa, Kazuhiro Hara \\ Tokyo Denki University, 5 Senju-Asahi-cho, \\ Adachi-ku, Tokyo 120-8551 Japan \\ hara@eee.dendai.ac.jp
}

\begin{abstract}
A xylene sensor using a double-layered metal-oxide thin film and a Ni-catalyst deposited on a porous alumina is presented. The sensing film has double-layered structure; the first layer is $\mathrm{Fe}_{2} \mathrm{O}_{3}+$ $\mathrm{TiO}_{2}(5 \mathrm{~mol} \%)+\mathrm{MgO}(4 \mathrm{~mol} \%)$, and the second layer is $\mathrm{WO}_{3}+\mathrm{TiO}_{2}(10 \mathrm{~mol} \%)$. The thickness of the first layer and the second layer is $200 \mathrm{~nm}$ and $70 \mathrm{~nm}$, respectively. Both the sensitivity and the stability are improved by adopting double-layered structure. The Ni-deposited porous alumina is placed over the sensing film. The pores in the porous alumina are cylindrical. The inner diameter and the height of the pores are about 200nm and $60 \mu \mathrm{m}$. Xylene gas goes through the Ni-deposited pores in the porous alumina to reach the sensing film. The catalytic action of the deposited $\mathrm{Ni}$ enhances the chemical activity of xylene gas. Thus the sensor is highly sensitive to xylene gas. Moreover, the selectivity to xylene gas is satisfactory. The sensor response time and recovery time are approximately 20 s and 300 s, respectively, at an operating temperature of $340^{\circ} \mathrm{C}$. All films and $\mathrm{Ni}$ are deposited by r.f. sputtering while the porous alumina is formed by anodic oxidation of aluminum.
\end{abstract}

Key words: xylene sensor, thin film, metal oxide, catalyst, porous alumina

\section{Introduction}

Xylene sensors using $\mathrm{SnO}_{2}$ nanoparticles and MWCNTs[1], poly(ethylene-vinylacetate) and a preconcentrator[2] and $\mathrm{ZnO}$ nanoparticles and nanorods[3] have been studied. However, they are not satisfactory in terms of sensitivity at several tens of ppb level of concentration. In this paper a highly sensitive xylene sensor using a double-layered metal-oxide thin-film and $\mathrm{Ni}$-catalyst deposited on a porous alumina is presented.

\section{Sensor configuration}

A schematic top and cross-sectional view of a proposed sensor is shown in Fig. 1. The sensing film has double-layered structure; the first layer was $\mathrm{Fe}_{2} \mathrm{O}_{3}+\mathrm{TiO}_{2}(5 \mathrm{~mol} \%)+$ $\mathrm{MgO}(4 \mathrm{~mol} \%)$, and the second layer was $\mathrm{WO}_{3}+$ $\mathrm{TiO}_{2}(10 \mathrm{~mol} \%)$. The thickness of the first layer and the second layer was $200 \mathrm{~nm}$ and $70 \mathrm{~nm}$, respectively. The material of the electrode was $\mathrm{Pt}+\mathrm{W}(5 \mathrm{~mol} \%)$, where $\mathrm{W}$ was added to increase the durability of the Pt electrode. The thickness of the electrode was $200 \mathrm{~nm}$.

Two sheets of mica membrane with a hole in the middle were used; the lower mica was used as a spacer to isolate the sensing film from the porous alumina while the upper mica was used as a protector to avoid possible damage to the porous alumina. The thickness of the lower mica and the upper mica was about $20 \mu \mathrm{m}$ and $100 \mu \mathrm{m}$, respectively.

All films were deposited by r.f. sputtering on an alumina substrate. The size of the substrate was $12 \mathrm{~mm} \times 12 \mathrm{~mm} \times 1 \mathrm{~mm}$. The electrodes and the sensing film were defined by photolithography. $\mathrm{Ni}$ was deposited at a thickness of $50 \mathrm{~nm}$ by r.f. sputtering on both sides of the porous alumina.

\section{Double-layered thin-film}

Most of metal-oxide thin-films tend to have cracks inside them through the following two processes.

(1) Metal-oxide films are subjected to high temperature annealing after deposition for the recovery from various defects and the stabilization of the crystal structure. In this process metal-oxide films shrink more or less as a result of sintering while its substrate usually expands as a result of thermal expansion. When the internal stress in the film exceeds a certain limit, cracks are generated to release the internal stress. 


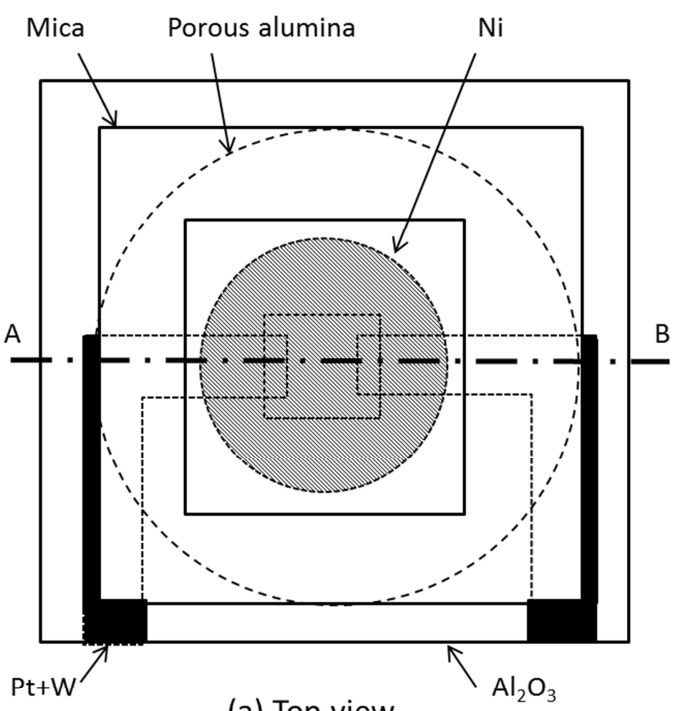

(a) Top view

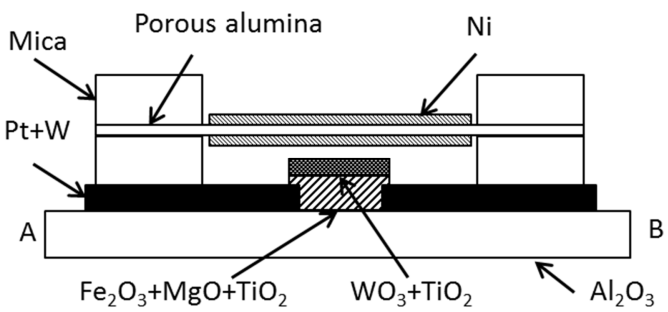

(b) Cross-sectional view

Fig. 1 Schematic top and cross-sectional view of a proposed xylene sensor using a doublelayered metal-oxide thin-film and a Ni-deposited porous alumina

(2) Metal-oxide films are inevitably subjected to a heat cycle between the room temperature and the operating temperature. The internal stress results from the difference in the thermal expansion coefficients between the film and the substrate, generating cracks inside films.

Both $\mathrm{SnO}_{2}$-based and $\mathrm{WO}_{3}$-based films are excellent materials in terms of sensitivity to a wide variety of gases. These materials, however, suffer from a disadvantage of having cracks that cause instability of the electric current, hence, the resistance or the conductance.

In contrast, $\mathrm{Fe}_{2} \mathrm{O}_{3}$-based film seldom have cracks inside them if it is deposited on an alumina or sapphire substrate because the crystal structure of $\mathrm{Fe}_{2} \mathrm{O}_{3}$ is corundum type and is the same as that of alumina or sapphire and the thermal expansion coefficient of $\mathrm{Fe}_{2} \mathrm{O}_{3}$ is close to that of alumina or sapphire. Thus $\mathrm{Fe}_{2} \mathrm{O}_{3}$-based film is stable since it is free of the adverse effects of cracks. However, it is not much sensitive to most gases.
A double-layered thin-film made of $\mathrm{SnO}_{2}$-based or $\mathrm{WO}_{3}$-based film on $\mathrm{Fe}_{2} \mathrm{O}_{3}$-based one utilizes both advantages of high sensitivity of $\mathrm{SnO}_{2}-$ based or $\mathrm{WO}_{3}$-based films and stability of $\mathrm{Fe}_{2} \mathrm{O}_{3}$-based one.

Figure 2 shows a schematic energy band diagram of a double-layered thin-film made of $\mathrm{WO}_{3}$-based film on $\mathrm{Fe}_{2} \mathrm{O}_{3}$-based one. In this film most of electrons flow in the $\mathrm{Fe}_{2} \mathrm{O}_{3}$-based film because the energy level of the conduction band in the $\mathrm{Fe}_{2} \mathrm{O}_{3}$-based film is lower than that in the $\mathrm{WO}_{3}$-based film. This is an important feature since the possible cracks in the $\mathrm{WO}_{3}-$ based film do not prevent the current flow. Thus the sensor resistance or conductance does not change in time. Note that the detected gas adsorbs or reacts with other adsorbed species on the $\mathrm{WO}_{3}$-based film that is highly active.

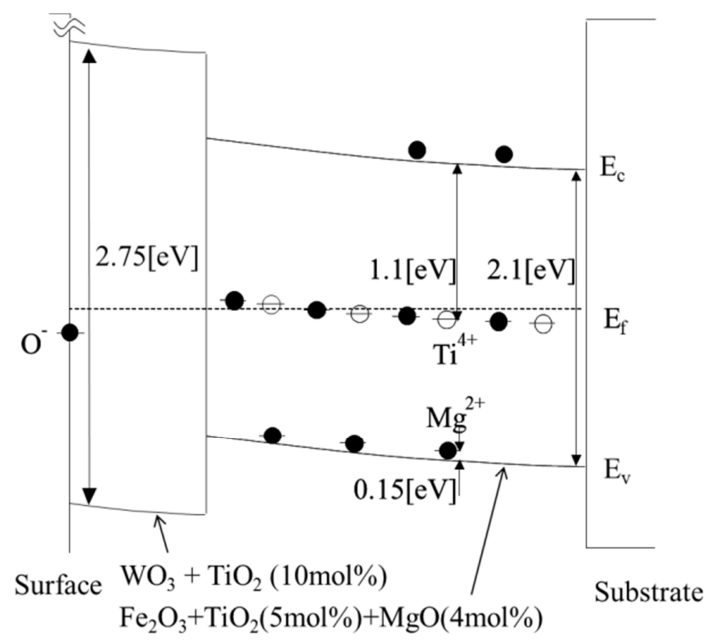

Fig. 2 Schematic energy band diagram of a double-layered thin-film made of $\mathrm{WO}_{3}$-based film on $\mathrm{Fe}_{2} \mathrm{O}_{3}$-based one.

\section{$\mathrm{Ni}$-deposited porous alumina filter}

A schematic enlarged top and cross-sectional view of a $\mathrm{Ni}$-deposited porous alumina is shown in Fig. 3. The porous alumina filter (Anodisc ${ }^{\mathrm{TM}}$, Whatman) is formed by anodic oxidation of aluminum. The pores in the porous alumina are cylindrical. The inner diameter and the height of the pores are about 200nm and $60 \mu \mathrm{m}$, respectively.

The thickness of the $\mathrm{Ni}$ catalyst is $50 \mathrm{~nm}$. $\mathrm{Pd}$ and $\mathrm{Pt}$ are also deposited on another piece of porous alumina for comparison. The thickness is $50 \mathrm{~nm}$ for both $\mathrm{Pd}$ and $\mathrm{Pt}$.

Xylene gas goes through the Ni-deposited pores in the porous alumina to reach the sensing film. The catalytic action of the deposited $\mathrm{Ni}$ enhances the chemical activity of xylene gas. 


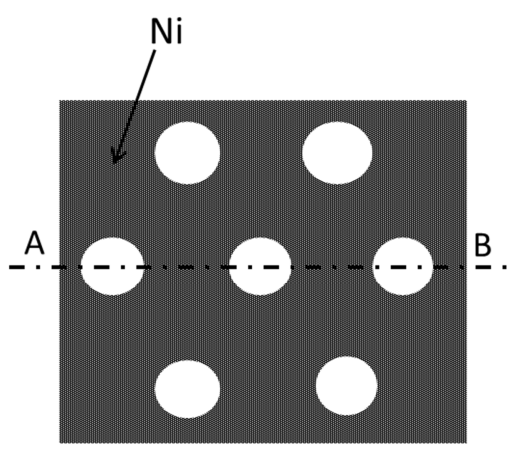

(a) Top view

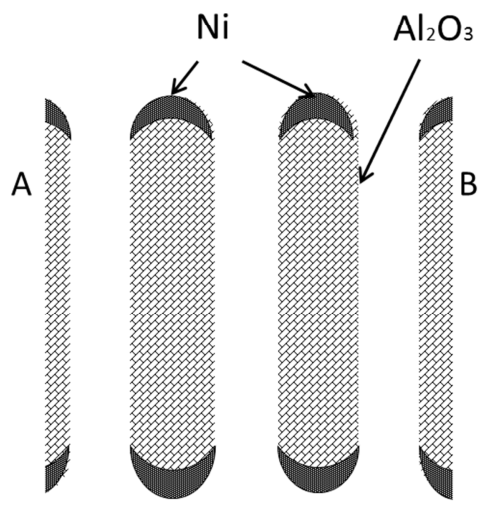

(b) Cross-sectional view

Fig. 3 Schematic enlarged top and crosssectional view of a Ni-deposited porous alumina filter.

The surface of $\mathrm{Ni}$ is likely to be oxidized to $\mathrm{NiO}$ while it is tested at high temperatures above $245^{\circ} \mathrm{C}$.

\section{Experimental results and discussion}

The sensor was heated on a heater in the temperature range from $245^{\circ} \mathrm{C}$ to $390^{\circ} \mathrm{C}$.

The sensor was sensitive to xylene gas among various gases. The sensitivity to xylene is shown as a function of gas concentration in Fig. 4. Here the sensitivity is defined as the ratio of the resistance in air to that in gas. The sensor was sensitive even at a concentration as low as 0.07ppm.

A transient response is shown in Fig. 5. The response time and recovery time are approximately 20 s and 300 s, respectively.

Figure 6 shows the temperature dependence of the sensitivity to xylene gas. The gas concentration was $1 \mathrm{ppm}$. The sensor with a Nideposited filter showed a maximum sensitivity around $340^{\circ} \mathrm{C}$. On the other hand, the sensor with a $\mathrm{Pt}$ or $\mathrm{Pd}$ filter showed little sensitivity to xylene.
Ni was effective in enhancing the sensitivity and selectivity to xylene gas in the temperature range from $245^{\circ} \mathrm{C}$ to $390^{\circ} \mathrm{C}$ while $\mathrm{Pd}$ and $\mathrm{Pt}$ were not. In general $\mathrm{Pd}$ and $\mathrm{Pt}$ are very active as catalysts which can increase the chemical activity of the target gas. In our case, however, $\mathrm{Pd}$ or $\mathrm{Pt}$ is supposed to oxygenate xylene gas so that the xylene gas does not reach the sensing film. In contrast, $\mathrm{Ni}$ is moderately active in enhancing the chemical activity of xylene gas and thus increases the amount of adsorption on the surface of the sensing film.

The gas selectivity of the sensor with a Ni filter is shown in Fig. 7. The gas concentration is 1 ppm and the operating temperature is $340^{\circ} \mathrm{C}$. It was found that the sensitivity to xylene was higher than that to the other gases. Thus the selectivity to xylene gas is satisfactory.

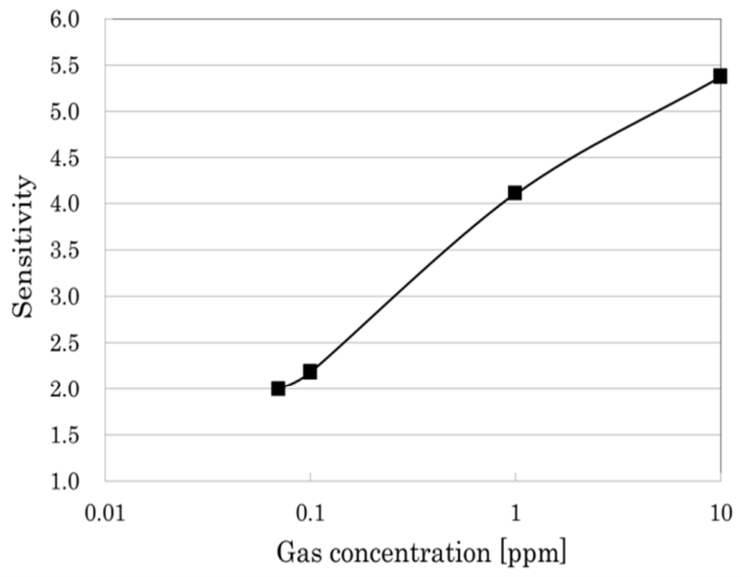

Fig. 4 Sensitivity to xylene as a function of gas concentration. The operating temperature is $340^{\circ} \mathrm{C}$.

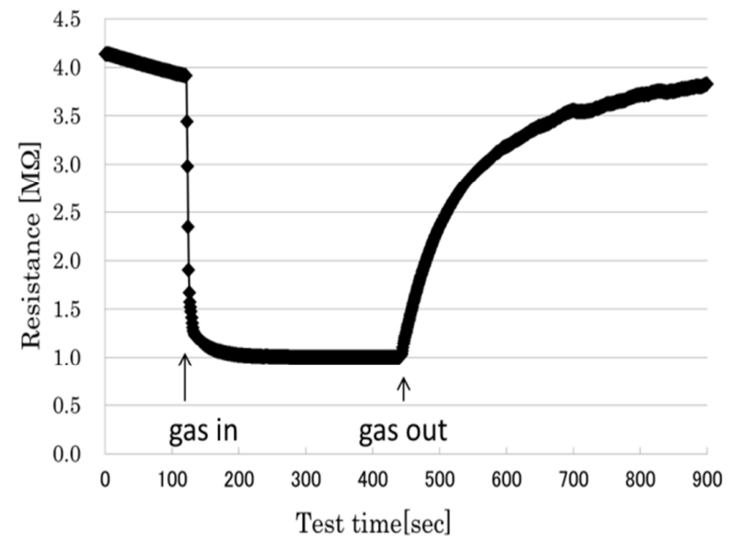

Fig. 5 Transient response to xylene at a concentration of 10ppm. The operating temperature is $340^{\circ} \mathrm{C}$. 


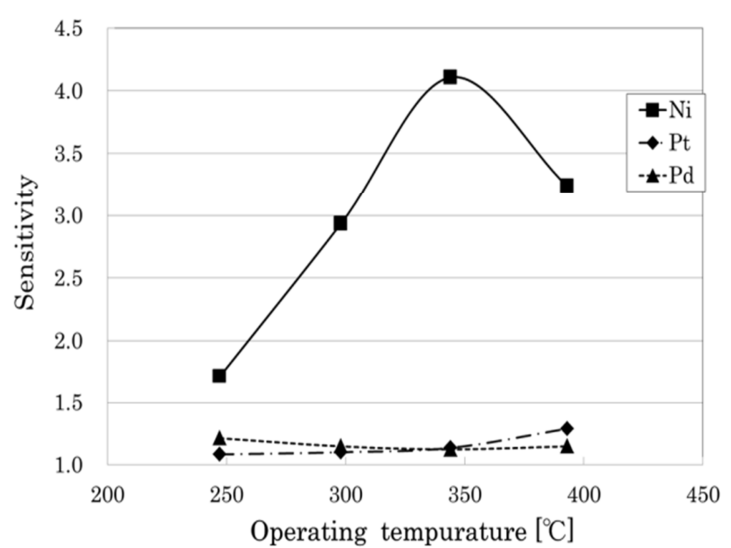

Fig. 6 Temperature dependence of the sensitivity to xylene gas.

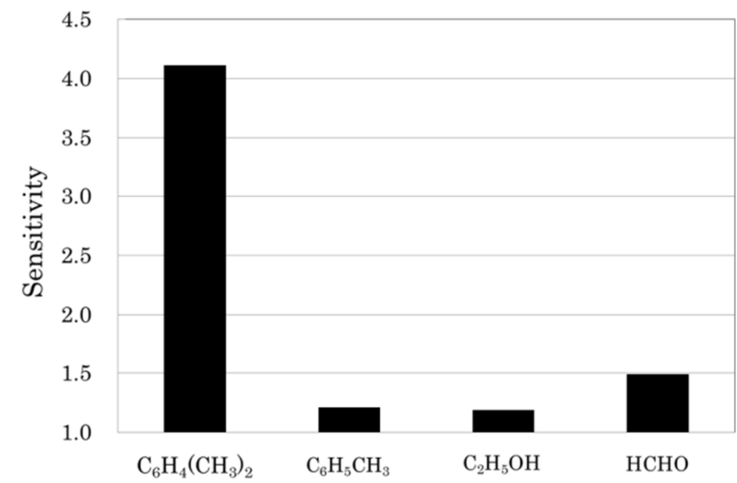

Fig. 7 Sensitivity to various gases.

\section{Conclusion}

A combination of double-layered thin-film and $\mathrm{Ni}$-catalyst deposited on a porous alumina was effective in enhancing sensitivity and selectivity to xylene gas. As the sensor uses neither expensive noble metals nor preconcentrators, it is a possible candidate for an inexpensive xylene sensor.

\section{References}

[1] K.-Y. Choi, J.-S. Park, K.-B. Park, H. J. Kim, H.-D. Park, S.-D. Kim, Sensors and Actuators B 150, 65-72 (2010); doi: 10.1016/j.snb.2010.07.041

[2] C.E. Davis, C.K. Ho, R.C. Hughes, M.L. Thomas, Sensors and Actuators B 104, 207-216 (2005); doi: 10.1016/j.snb.2004.04.120

[3] Y. Cao, P. Hu, W. Pan, Y.Huang, D. Jia, Sensors and Actuators B 134, 462-466 (2008); doi: 10.1016/j.snb.2008.05.026 